\title{
Metaplastic carcinoma of breast
}

\author{
Dewasi $\mathrm{N}^{1}$, Bhattacharya $\mathrm{D}^{1}$, Sarkar $\mathrm{PG}^{2}$, Das $\mathrm{M}^{3}$, Ghosh $\mathrm{S}^{4}$, Ghosh $\mathrm{TK}^{5}$ \\ ${ }^{I}$ Department of Pathology, Burdwan Medical College, Kolkata, India \\ ${ }^{2}$ Department of Surgery, R.G. Kar Medical College, Kolkata, India \\ ${ }^{3}$ Department of Microbiology, School of Tropical Medicine, Kolkata, India \\ ${ }^{4}$ Department of Pathology, Calcutta National Medical College \& Hospital, Kolkata, India \\ ${ }^{5}$ Department of Pathology, Bankura Sammilani Medical College \& Hospita, Bankura, India.
}

\section{Keywords: \\ Metaplastic carcinoma; Breast.}

\section{ABSTRACT}

Abstract: Metaplastic carcinomas of breast are a heterogeneous group of malignant tumours in which part or all of the carcinomatous epithelium is transformed into a nonglandular (metaplastic) growth process. This rare neoplasm usually runs an aggressive course.

\section{INTRODUCTION}

Metaplastic carcinomas are rare and it is thought to constitute between 0.21 and $5 \%{ }^{2}$ of all breast cancers. In addition to epithelial elements, these uncommon tumours may contain other cellular components. ${ }^{3}$ These sarcomatous elements range from cartilage, bone, myxoid changes and spindle cell components. ${ }^{1}$ These tumours may manifest as wellcircumscribed or irregular speculated mass. ${ }^{4}$ These tumours can be classified as monophasic spindle cell (sarcomatoid) carcinoma, biphasic carcinosarcoma, adenocarcinoma with divergent stromal differentiation (osseous, chondroid, and rare rhabdoid) as well as adenosquamous and pure squamous cell carcinoma.

These carcinomas can metastasize to any part of the body. It is difficult to assess the prognosis of metaplastic carcinoma because of their relative rarity, but may behave as highly malignant tumours with early recurrence and poor survival. ${ }^{1}$

Both the cases were collected from Department of Pathology \& Surgery of Burdwan medical college and RG Kar Medical College in July 2012 and April 2013. Hematoxylin

\section{Correspondence:}

Dr. Pran Gopal Sarkar,MD

Associate Professor,

Department of Pathology, R.G.Kar Medical College. Kolkata

E-mail-pgsarker@gmail.com
$\&$ Eosin stain were done from routinely processed paraffin embedded blocks after gross examination of the surgical specimen. Immunohistochemistry stains of cytokeratin and vimentin were done afterwards.

\section{CASE REPORT}

\section{CASE \# 1}

A 45 year-old-female presented with a lump over right breast in upper outer quadrant more towards the midline for last 2-3 months in surgical OPD. Clinically the mass was about $8 \times 5 \times 4 \mathrm{~cm}$, firm, nodular, fixed to the skin. No lymphadenopathy was seen. FNAC was done which showed poorly cohesive spindle cells suggestive of pleomorphic sarcoma. The mastectomy specimen was sent to the department of pathology for histopathological examination.

On gross examination, the tumour was well circumscribed, firm, nodular, measuring about $8 \times 5 \times 4 \mathrm{~cm}$ and was fixed to the skin. Cut surface was grayish-white, solid fleshy with some foci of hemorrhages. (fig.1)

Microscopic examination revealed malignant glands admixed with pleomorphic spindle cells with hyperchromatic 


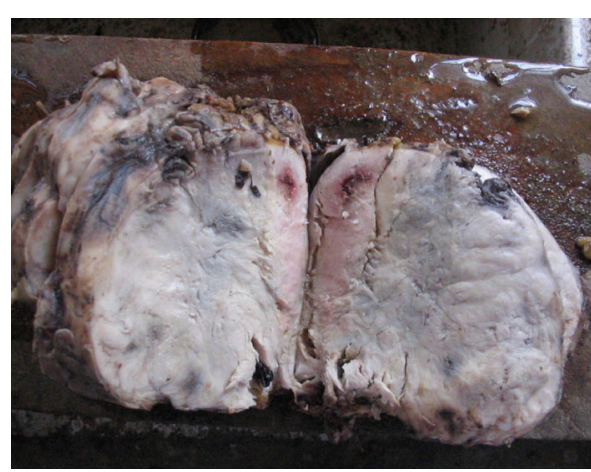

Figure1: Gross picture showing the tumour about $8 \times 5 \times 4 \mathrm{~cm}$, well- circumscribed, nodular mass

nucleus and increased mitotic count. The sarcomatous stroma showed as malignant fibrous histiocytoma like elements, also had osteoid formation and chondromyxoid substance at places (fig.2). Immunohistochemistry demonstrated Vimentin and Cytokeratin positivity (fig.2 \& 3 ). It was diagnosed to be a case of metaplastic carcinoma of breast.

\section{CASE \# 2}

A 26 years-old-female presented with a lump over right breast in upper quadrant for last 5-6 months in surgery department. Clinically the mass was $4 \times 3 \times 2 \mathrm{~cm}$, firm and fixed in deep fascia. On gross examination, multiple small pieces of grayish white tissue received. All the pieces were embedded. Microscopic examination revealed a tumour composed of ovoid cells with pleomorphic vesicular nuclei and prominent nucleoli. Tumour giant cells are seen. The tumour exhibits brisk mitotic activity. There are extensive areas of tumour necrosis. No ductal elements were identified. An impression of compatible with metaplastic carcinoma breast was given. The possibility of malignant phylloides tumour was considered in the differential diagnosis. However the diagnosis of metaplastic carcinoma has been favored as no ductal elements could not be demonstrated and immunohistochemistry proved presence of both epithelial and mesenchymal elements (vimentin and cytokeratin).

\section{DISCUSSION}

Though metaplastic carcinomas are malignant neoplasms composed of both epithelial and mesenchymal elements, pathogenesis of such diverse elements within obvious infiltrating carcinomas has been the subject of much controversy. But since the tumours show cytokeratin positivity in both epithelial and mesenchymal elements the term 'metaplastic carcinoma' has been designated to them.5 Metaplastic breast carcinoma is rare. It is thought to constitute between 0.21 and $5 \%^{2}$ of all breast cancers. The term describes a range of cancers of mixed epithelial and mesenchymal origin., ${ }^{2,6-8}$ As seen in the first case of this series and the degree of differentiation varies from

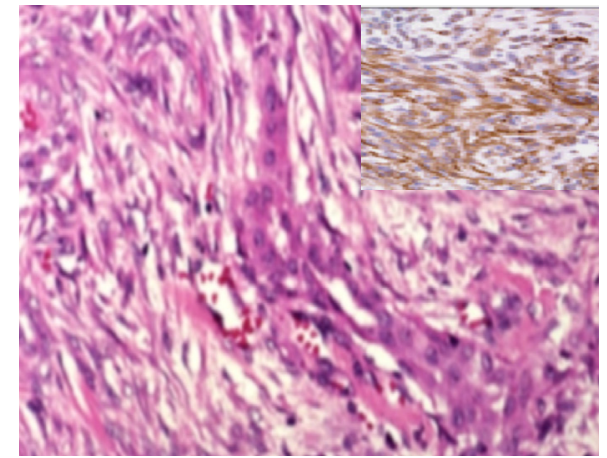

Figure2: Photomicrograph showing area of glandular formation surroumded by spindle cells (HE stain, X400). Inset showing cytokeratin positivity.

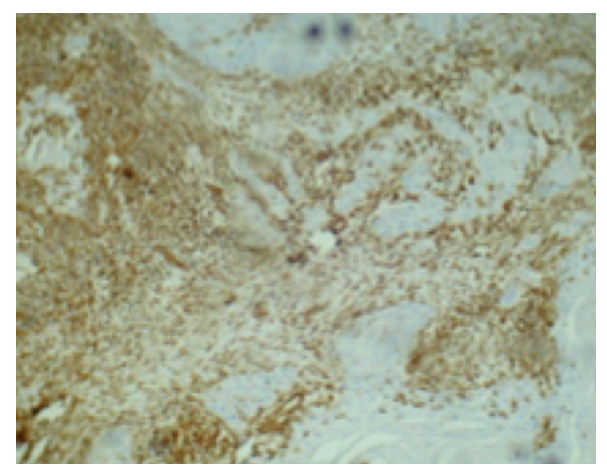

Figure 3: Photomicrograph Showing Vimentin Positivity (X100).

small foci to complete glandular replacement as seen in the second case of this series. ${ }^{69}$ Microscopically, the tumour can show a pure spindle cell pattern or mixed epithelial and mesenchymal pattern. Metaplastic carcinoma is a rare tumour of breast consisting of intraductal or infiltrating carcinoma. Contagious or subtly merged with high cellular mitotically active pleomorphic spindle cell stroma. ${ }^{10}$ Carcinomas showing extensive metaplastic change to spindle cells, squamous cells and heterogeneous mesenchymal elements as well recognized in breast. ${ }^{11}$ The tumour shows varying proportion of carcinomatous and pseudosarcomatous elements as seen in first case of this series.

The differential diagnosis of metaplastic carcinoma includes other common and rare primary breast carcinoma, primary sarcoma of breast, phylloides tumour, lymphoma, adenomyoepithelioma, carcinoma with osteoclast like giant cells, metaplastic carcinoma and some benign entities. The correct diagnosis relies on immunohistochemistry of two cases by presence of invasive ductal carcinoma along with other metaplastic elements by immunohistochemistry. 8 Most of the tumours present as large, firm, nodular tumours, often measuring up to $5 \mathrm{~cm}$ in diameter. Fixation to skin or deep fascia is not uncommon which are consistent with the two cases in the series. ${ }^{1}$ 
In case of metaplastic carcinoma of breast with spindle cell differentiation, the possibility of a phylloides tumour has to be ruled out which was done in the second case considering the presence of no malignant glandular elements. Metaplastic carcinoma of the breast is an aggressive form of breast cancer is associated with poor outcome, high incidence of local recurrence and pulmonary metastases. ${ }^{12}$ The present cases had no evidence of pulmonary or any other distant metastases.

Immunohistochemistry is of particular value in evaluation of the tumours that lack evidence of carcinoma. The sarcoma liker elements of these tumours may have acquired vimentin positivity and other features of mesenchymal nature; it is always possible to demonstrate epithelial markers (wide spectrum cytokeratin positivity) in at least occasional cells. ${ }^{13,14}$

\section{CONCLUSION}

In conclusion, metaplastic carcinoma of the breast, although rare, have to be diagnosed and excised at the earliest as these tumours have a poor outcome.

\section{REFERENCES}

1. Fletcher CD. In Diagnostic Histopathology of Tumours. 2nd ed.: Churchill Livingstone; 2000. pp.900.

2. Johnson TL, Kini SR. Metaplastic breast carcinoma: a cytohistologic and clinical study of 10 cases. Diagn Cytopathol1996;14:226-32. CrossRef

3. Agarwal K, Kaur M, Bajaj P, Agarwal C, Pathania OP. Metaplastic carcinomas of the breast (light microscopic and immunohistochemical features). Indian J Cancer 2001;38:80-4.

4. Kiran A, Veena M, Hasan H, Ghazala M. An usual case of metaplastic breast carcinoma( sarcomatoid variant). Indian J Surg 2003;65:377-8.

5. Saxena S, Bansal A, Mohil RS, Bhatnagar D. Metaplastic carcinoma of the breast: A rare breast tumour. Indian J Pathol Micrbiol 2004;47:21720. PMid:16295473
6. Rosen PP. Invasive Mammary carcinoma. In Harris JR, Lippman ME, Marrow M, Hellman S. Diseases of the Breast. Philadelphia,New York: Lippencott-Raven;1996.pp411-3.

7. Kaufman MW, Marti JR, Gallagher HS, Hoehn JL. Carcinoma of the breast with pseudosarcomatous metaplasia. Cancer 1984;53:1908-17. CrossRef

8. Elston CW, Ellis IO. The Braast. In Systemic Pathology. 3rd ed.: Churchill Livingstone, Edinburugh; 1998. pp 323-28.

9. Rosen PR, Oberman HA. Atlas of tumour pathology.Tumours of the Mammary Gland Washington DC: Armed Forces Institute of Pathology; 993.

10. Gogas J, Kouskos E, Markpoul C, Mantas D,et al. Carcinosarcoma of the breast: a review of two cases. EurJ Gynaecol Oncol 2003;24:93-5. PMid:12691330

11. Juan R, editor. The Breast. In Rosai \& Ackerman's Surgical Pathology. 9th ed: Mosby; 2004. pp1763-876.

12. Al Sayed AD, El Weshi AN, Tulbah AM, Rahal MM, Ezzat AA. Metaplastic carcinoma of the breast clinical presentation, treatment results and prognostic factors. Acta Oncol 2006; 45:188-95. CrossRef

13. Adem C, Reynolds C, Adlakha M, Roche PC, Nascimento AG. Wide spectrum screening keratin as a marker of metaplastic spindle cell carcinoma of the breast: an immunohistochemical study of 24 patients. Histopathology 2002;40:556-62. CrossRef

14. Tokudome N, Sakamoto G, Sakai T et al. A case of carcinosarcoma of the breast.Case report. Breast cancer 2005;12:149-53. CrossRef 